\title{
ASSESSMENT OF TOTAL QUALITY MANAGEMENT ACCORDING TO STRATEGIC PLANNING: A CASE STUDY FOR A BUSINESS IN THE TEXTILE-APPAREL INDUSTRY
}

\author{
DOI: 10.17261/Pressacademia.2020.1279 \\ RJBM- V.7-ISS.3-2020(4)-p.157-168
}

\author{
Aysenur Erdil \\ Istanbul Medeniyet University, Istanbul, Turkey. \\ aysenurerdil@gmail.com , ORCID:0000-0002-6413-7482
}

Date Received: June 17, 2020

Date Accepted: September 3, 2020

To cite this document

Erdil, A., (2020). Assessment of total quality management according to strategic planning: a case study for a business in the textile-apparel industry. Research Journal of Business and Management (RJBM), V.7(3), p.157-168.

Permanent link to this document: $\underline{\text { http://doi.org/10.17261/Pressacademia.2020.1279 }}$

Copyright: Published by PressAcademia and limited licensed re-use rights only.

\begin{abstract}
Purpose- After evaluating the core elements and general concepts of Total Quality Management (TQM) through extensive literature analysis, the objective of this study is to adapt it to a company in order to search these principles totally out. This company, which is one of firms of the textile-apparel sector in Turkey, is preferred for this direction because its management team already is notified about TQM's highlights and supports application.

Methodology- Strategic overview, in the business context, is an important principle and the main aim of every organization would be to obtain it. TQM is about sustainability of improvement of individual, group and organizational performance. The main focus on continual improvement is what distinguishes TQM from other management practices. TQM is not a potential fix; it's about continuously improving the way issues are applied. Most companies are applied TQM strategies in today's environment to gain sustainable business advantage.

Findings- The analysis shows that the implementations start with the preparation of some survey questions for all of the corporation's current employees, its people, consumers and people working in this company to find out their degree of satisfaction, since TQM includes discovering the points due to quality influence where they are dissatisfied with the business and promoting the business. By using a systematic approach, the results are analysed in depth. Assessment values are summarized with the contribution of the management.

Conclusion- This enables the difference between its expectations and actual results to be highlighted. Any recommendations for the organization are given at the end of the study, based on the assessments.
\end{abstract}

Keywords: Business, strategic, textile-apparel sector, total quality management (TQM).

JEL Codes: E32, L19, M11, Z31

\section{INTRODUCTION}

Over the last thirty years, the business environment has been changing at an ever increasing rate. It has come from a number of causes, including advancement of technologies, globalization, and globalization and growing desire for quality products and services from consumers. It is increasingly understood that quality and consumer loyalty goods and services are essential to sustainability for every business.

Quality has become one of the most important consumer decision factors in the selection among competing products and services. It is a fact that the word of "quality" has not a determined and specific mean. Everyone can define quality with respect to his/her thought. Now a few of this definition will be given. The total composite product and service characteristics of marketing, engineering, manufacture, and maintenance through which the product and service in use will meet the expectations of the customer. Statistical Process Control (SPC) is the most popular way of getting high quality products from a manufacturing process. It is also the main subject of Quality Control and Total Quality Management (TQM). Thus, this is necessary to make the implementation according to the subject. The choice of competitive services and products has made quality one of the most significant aspects for customer perception. Whether the consumer is an individual, an industrial 
company, a retail organization or a militant defense program, the phenomenon is widespread. Therefore, understanding and quality improvement is a key factor that leads to success, growth and increased competitiveness. Improved quality and successful use of quality as an integral part of the overall business strategy have significant returns on investment. To consider taking a global perspective and concepts and theories about quality management, it is important to understand the entire monitoring system as a new management approach (Oakland, 2005; Samat et al., 2000; Wilkinson, 1992). TQM is a concept that is rooted in the continuous improvement of market results and the consistency of the products generated by these operations; it is also a holistic management process, geographically restored over an organization and which includes both divisions and staff and applied retrospectively to cover all vendors and consumers. TQM as an administrative technique of a corporation that sets itself firmly by its Quality Assessment to ensure the institute Efficient application of total quality management (TQM) in organizations has become a major topic for the workers detailed consumers, workers, professionals and profitable institutions who serve directly or indirectly within a company (Qaiser \& Rizwana, 2015; Ngambi \& Nkemkiafu, 2015). If workers become interested with different organizational procedures and are educated to become more professional, a TQM campaign cannot succeed (Khanna \& Gupta, 2014). Many scholars believe that human resources (individuals) are crucial to enforcing quality control strategies, since humans are also the major factors in operations (Zhou, 2012). High-leadership organizations conduct every of the nine TQM Principles are more successful and able to deliver output of better quality (Das et al., 2011). Competencies relate to managers' talents, knowledge, personalities and actions within the companies' context. A healthy combination of these qualities fosters professional growth synergies, fosters the attention of staff, customers and organizations, and contributes to superior results (Plessis \& Beer, 2010). Today's market challenges faced by companies, that is, globalization, competitiveness through production, and technological progress. Achievement subsequently depends on developing the organizational competencies, such as tempo, responsiveness, cognitive ability (Gupta et al., 2012).

The European Framework for Quality Management (EFQM), the Swedish Quality Award (SIQ), and the Malcolm Baldrige National Quality Award (MBNQA) are the various evaluation frameworks that define the TQM compliance requirements while taking into consideration its core principles. The American MBNQA approach combines soft as well as hard facets of TQM and has been found to be immensely useful in terms of incorporating changes to the strategic and organizational processes across both public and private organizations. This paradigm incorporates six elements, including leadership, strategic strategy, consumer attention, performance management, human resource management, and knowledge and review, and has been extensively studied by numerous scholars, including Yusr et al.(2017), Ooi (2014), and Sila (2007). TQM is a method of management that emphasizes on continual change by resources, strategies and principles (Mahmood et al., 2014). The past several decades also seen TQM's major involvement in corporate policies. Being a systematic method of management, TQM strives for quality growth in all aspects of the company (Abbas, 2019). This attribute contributes closely to sustainability (Li et al., 2018). Management leadership serves as a guiding factor in the adoption, growth and progress of TQM through a corporate climate that is agile, creative and stakeholder driven. The leaders' engagement has to be influenced by priorities, objectives, and initiatives that allow the organization to produce greater success (Rahman \& Bullock, 2005). In this context, the way the equipment, software and network services are handled and distributed is a crucial factor in determining the contribution of management to quality (Fotopoulos \& Psomas, 2010). The maintenance of partnerships with the major supply providers and other stakeholders is a core aspect in every organization's approach in the new market climate (Vanichchinchai and Igel, 2011). In the other side, the success of certain strategic TQM considerations such as product design and development, project control and the usage of quality assurance techniques include employee involvement by comprehensive preparation, encouragement and coordination (Seinor and Swailer, 2004). From the academic point of view, there are certain researches which have the study and interpretation of how the concepts of success function as their core aim. Most common are those evaluating performance processes focused on universal ISO 9000 principles or other quality control and development methods including such benchmark tests, Six Sigma, Just in Time, Lean, Enterprise Resources Management and the Balanced Scorecard (DahlgaarPark et al., 2013). Prajogo and Sohal described two contradictory claims in a study of the literature that concerns the interaction between TQM and creativity. The first statement indicates that TQM is positively linked to success in innovation as it creates a structure and community that will provide companies with a productive atmosphere to innovate (Roffe, 1999; Kanji, 1996; Mahesh, 1993). The supporting claim suggests that applying the concepts and methods of TQM could impede organizations from becoming innovative (Samaha, 1999; Wind \& Mahajan, 1997). Customer oriented theory has gained substantial publicity in relation to its harmful impact on competition from many main concepts of TQM (Slater \& Narver, 1998; Wind \& Mahajan, 1997).

Dean and Bowen suggest though from an organizational development viewpoint, TQM is somewhat more obsessed with execution of the plan, or delivery, than with strategic option, or purpose. Thus, the problem is to examine which specific TQM approach may be related to. Reed et al. suggest that TQM's material should be differentiated on the basis of two market orientations: customer orientation and method orientation. With consumer awareness, companies should concentrate on 
achieving a business edge, where they might underperform their rivals by drawing more consumers for respected services and paying a higher price. Though not expressly mentioned, this notion implies that TQM is correlated with a policy of distinction under consumer orientation. In the other side, businesses would be seeking production quality changes to minimize errors and losses within product orientation. This perspective can be traced back to TQM's beginnings as grounded in Statistical Process Control (SPC) concepts. The principle of kaizen that dominated TQM literature throughout the 1980s and 1990s often underlined the value of developing procedures rather than innovating goods (Reed et al., 1996; Imai, 1986). Many of the often addressed issues relating to philosophical aspects are (i) challenges in determining what TQM is, (ii) how to categorize different levels and subgroups, (iii) what to include and what to remove under the TQM umbrella, (iv) what concepts are reasonable to use in the order to categorize, (v) what are the interactions between TQM, BE, Lean, and 6s, and (vi) is TQM unusual? The misperceptions were either about philosophical issues or about regarding the application / functional dimensions of QM (Dahlgaard-Park et al., 2013).

According to this subject, the main objective of this study, after researching important features and basic principles of TQM through a thorough literature review, is to extend it to a company to thoroughly explore such principles. This company, which is one of the businesses in the apparel industry in Turkey, is preferred for this target because its top management is already aware of the advantages of TQM and encourages its application. Implementations of this study starts with the preparation of certain survey questions for all employees of the company, its consumers, the people working in an organisation to find out their degree of confidence, since TQM involves the identification of points due to statistical process control where they are dissatisfied with the business and promote the company. Evaluations are evaluated in depth using a systematic approach in the last part of the research. The results of the assessment are highlighted with the guidance of the management. It illustrates the disparity between the goals and the real outcomes. Several suggestions-recommendations for the organization are given at the end of the report, based on the importance of the research. Some comments for the corporation are addressed at the completion of the research in accordance with the assessments.

\section{LITERATURE REVIEW}

\subsection{Background of Quality Management}

Since the Second World War there have been several significant developments after centuries when the principles of quality and quality control have evolved dramatically. Quality management (QM) began with simple inspection systems in which a company traditionally employs inspection teams to examine measure or test products and compare them to a product standard. That will happen to all phases of the development of products including the landscape, research in progress and shipping. The system was based on the inspectors' finding of poor quality products from good quality. This is then dismantled, reworked or sold in lower quality. Several outcomes have been obtained (Jabonski, 1994; Johnson, 1993; Kanji \& Asher, 1993; Berry, 1991). The statistical inference quality monitoring (SQC) theories developed by Walter Shewhart, scientist from the Bell Laboratories. Shewhart suggested that control of production processes is much more effective than inspection of endpoints for quality assurance and improvement. Over certain years, total manufacturing requirements, standard checks and evaluations have been used to track the management of quality and insure the standards are met (Anderson, 2010; Yong and Wilkinson, 2002).

During the Industrial Revolution, the abilities of trainees working for skilled craftsmen and qualified trainees were achieved and their quality was guaranteed and defective goods were not given to the customer. In the conditions of time and high efficiency, this traditional method was successfully applied. Operative control of quality as a craftsman who was fully controlled throughout his production process and who asserted the performance of the goods successfully completed. In addition, the original research by Shewhart (1939) on improving the process of statistic control (SPC) and PDCA (Plan Do Test Act) had an immense effect in that area. However, the origins of engineering devices date from the 1930s and innovation still persists (Schroeder et al., 2005; Yong and Wilkinson, 2002). To increase the efficiency of the operations, organizations adopt different efficiency management (QM) activities. Experts believe that QM activities are scientifically as well as behaviorally based methods. The correlation between performance-oriented technological and interpersonal strategies has contributed to paradoxical partnerships. Improving efficiency in quality involves recognizing the connection between technologically and behaviorally driven methods (Cho et al., 2017).

The absence of an overall analytical structure defining the role of QM activities in strategic planning contributed to the advent of severability clause-based strategies (Jusoh \& Parnell, 2008; Sousa \& Voss, 2008; Simpson et al., 2012; De Clercq et al., 2014; McAdam et al., 2016). Having established the question or phenomenon of SME strategy implementation as the point of reference for the analysis of QM theoretical development, contingency-based theory construction is required to demonstrate which QM techniques can affect strategic alignment. This observation is concerned with the description of concept by Gioia and 
Pitre (1990) as a description of topics and their interconnections which demonstrate how a problem exists, or why. Contingency theory has arisen as a tool for investigating the linkages between strategic planning and QM processes (Garg and Goyal, 2012; Raymond and St-Pierre, 2013; McAdam et al., 2016) and allows a variety of contingency factors or variables (CVs) to be defined immediately. QM provides a variety of views on its effect on performance, reliability and standardization with respect to its effects on quality, growth and creativity (Backström et al., 2017). Nonetheless, the desire to merge the two sides of this continuum remains impossible to apply in reality. This is somewhat shocking, considering that the original aim of QM was to increase service for clients of practitioners (Fundin et al., 2017). Yeung et al. (2004) has demonstrated how QM activities fit with business objectives in a survey of 225 Hong Kong-based electronics firms. However, following this optimistic observation, the authors have observed substantial misalignment between QM theory and reality, owing mainly to the complex, rapidly evolving operating environment. In view of the fact that the Yeung et al. (2004) thesis was (a) undertaken over a decade ago and (b) focused on a single industry in a single geographic region, it would be worth revisiting the issue of whether research into QM and Practice is distorted. As such, this review seeks to recognize the issues that QM professionals are facing and help appreciate how recent QM work approaches them.

The systemic approach known as Total Quality Control (TQC) was founded by Deming as Edwards Deming, an American statistician and physicist. The results of a system involving interlinked processes according to him are quality. Ishikawa has defined TQC as company-wide quality control. Quality was the outward domain of QC (Quality Control) experts, but Japanese culture indicates that everybody in all business units join, exercise and research quality control. The productivity responsibility for all workers is generally worked out rather than by a professional profession. TQM is a strategy to continuously increasing the quality of received products and services by engaging all levels and organization functions (Yong \& Wilkinson, 2002; Samat et al., 2002; Wilkinson, 1992). Four P's are essential to supplying consumers with premium goods and services. The following four Ps are: Planning - includes policy development and implementation and Techniques; the creation and product management of effective alliances and services. Performance - including the establishment of a metric system for results; an organization's healthy scorecard self-assessments, evaluations, feedback and benchmarking. Processes - involves process awareness, implementation, creation and redesign; frameworks for controlling quality; continuing improvements. People- Human resources management; changing culture; coordination; individuals; Development and continuing to learn; communication processes (Oakland, 2005, Oakland, 1993; Ross, 1993). TQM's principal goal is to include a management structure and organizational culture that requires a systemic mechanism of continuous enhancement of company processes which would also increase the standard of services TQM provides (Dedhia, 2005; Samat et al., 2002).

\subsection{Perception for the Management of Total Quality}

While many suggestions for successful implementing changes exist, there is no tried and true way of ensuring a successful experience of change. Although the transition is specific to company and management, companies that plan to make a shift have several different choices, recognized as commandments for change. These are listed as below (Keleda, 1996; Powell, 1995; Bounds et al., 1995; Porter \& Parker, 1993);

1. The evaluation and the need for modification of the organization: this assessment should comprise the background, operational aspects, the effectiveness of the business as well as its strengths and weaknesses at various levels of the organization.

2. Establish a shared vision and direction: The vision is an effort, in sometimes grandiose terms, to express the desired future business. Strategic objectives should be short and up-to - date and should be equally anxious and powerful.

3. Separate from the past: even though hanging onto certain components of organizational structure, such as the destination, mythologies or culture and history, is also essential to take a close look at what activities and frameworks no longer perform and try to get beyond them

4. Set an urgent feeling: The pioneers of organizational reform will create a sense of urgency by thoroughly explaining the condition and speaking to the company itself continuously. TQM data can be presented to organizational members about customer fulfillment, competitive forces, and the need for satisfaction as a status to understand the need to achieve TQM systems.

5. Respect the effective leadership position of every company without the assistance of members who can be seen as tools to transformation, even for the TQM. Top management supports and promotes a vision of TQM culture, aligns employees with a vision and leads to change 
6. Policy sponsorship alignment: Implementers must be able to accept TQM's focus on communication, synergy and staff involvement from those who are the receptors of change, as key sponsors.

7. Craft an implementation plan: Organisations need to have implementation plans that map out key events, steps, and processes the plan should enable the organisation to bridge the gap between what is and what should be. Implementation plans must be designed with the needs of specific organisations in mind.

8. Development of capable structures: changing the status quo and developing new ways of organizing, measuring and evaluating progress are essential to any organizational changes. Many realistic solutions such as product tests, seminars and preparation, or visual frameworks such as flags, gatherings or going through a team's office room may be used.

9. Communicate, connect individuals and remain honest: efficient leadership from the start of a change effort is critical every dimension of modification has to be mentioned, outlined and discussed at various managerial levels.

10. Supporting and institutionalizing change: administrators highlight the importance of transition by reinforcing their current behavior, and Senior Management engagement is evident and seen every day.

Quality oriented evaluation for publication by a recognised body of standards that includes guidelines, specifications or protocols for an organized approach to a particular task. It can contain specifications for product construction, research procedures, classifications, best practices and other factors. It defines safety criteria which are meant to minimize accident risk. Quality oriented has several advantages: It sets commodity value thresholds. They are a quality-process system. It cuts prices, and saves time and money. A collection of practices or strategies whose aim is to determine that all quality criteria are met by inspection and testing via tracking processes and addressing quality issues.

\subsection{TQM Advantages and Developments}

Generally, TQM (Total Quality Management) has three main advantages and benefits in terms of enhancing profitability and competence, enhancing business efficiency, and improving customer satisfaction. Improved profitability and competitive performance and competitiveness of companies (for instance market shares, growth, and investment revenue) are definitely enhanced by improving product and service quality. Higher costs minimize promotions, repeat sales and greater customer shares provide the gains of better quality facilities. Businesses with advancement quality are important and quality of the product is increasing faster, which is an important component of business profit growth. A quality distinguishing strategy based on the customer can often not only lead to customer satisfaction but also to an increase in sales volume and reduced prices (Powell, 1995; Bounds et al., 1995; Porter \& Parker, 1993; Cartin, 1993). TQM allows a corporation, by developing and simplifying its business process (efficiency), to generate more with its existing capabilities and, for the first time, to do more with a greater awareness of internal and external customer requirements (effectiveness). This increase in efficiency and effectiveness can reduce total costs, decrease customer sales, increase sales and even attract new customers at lower marketing expenses. A good end result does not actually impact outcomes, but in the long run.

The main goal of this research is to use it to an enterprise to find out these important concepts after examining the key elements and conceptual frameworks of TQM through extensive literary studies. This company has been chosen for this destination, since its senior management is already aware of and supports the advantages of TQM. It is one of the companies in textile industries in Turkey. The results of the assessment are stated through the management's commitment.

\section{DATA AND METHODOLOGY}

\subsection{Production for Apparel-Textile Industry}

Apparel is one of the industries where consequential-significant phases of the generation in the industrialised-technical politically organized bodies of households under a single government have been established much more or fewer parallel to this sourcing of producing. Research and Development is the fundamental of this industry. It bases on developing and producing new products to meet consumer demand and find ways to produce these products. Moreover, the relative frequency via which modern goods are defined has accumulated (so-named fast fashion) and the consuming - using up of garments in the industrialised lands-cities-locations have become larger. The Second important issue is marketing of Products of this business which all activities involve in creating and selling profitable Products. Manufacturers must decide what raw materials to buy and what fabrics to manufacture and they base their decisions on careful studies of what customers want (Macchion et al., 2015; Morgan \& Birtwistle, 2009; Martinich, 1997). 
Apparel is one of the basic necessities of human civilization along with food, water and shelter. The textile industry is real dealt out and various sector with a universal framework in large stages of the industry, where producing and consuming appear in various locations-places and sometimes various subcontinents. The apparel goods chain structure circular from the generation of raw matters (fibres). This growing consumption has become parallel-collateral with differences in the development policies in the apparel sector approaching what is named fast fashion. Apparel Production Segment includes all people and processes involved in designing and making garments (Macchion et al., 2015; Morgan \& Birtwistle, 2009).

In a very short time, $\mathrm{ABC}$ Company has a vision and can be a leader in the clothing sector of children and teenagers and created a new trademark in Marmara Region. This business consists of design, product management, sampling, human resources, finance, product development, and sales and marketing departments. Process Sequence of Apparel Manufacturing of this company is presented as below in Figure 1.

Figure 1: Process Progression of the Manufacturing of Apparel (ABC Apparel Company)

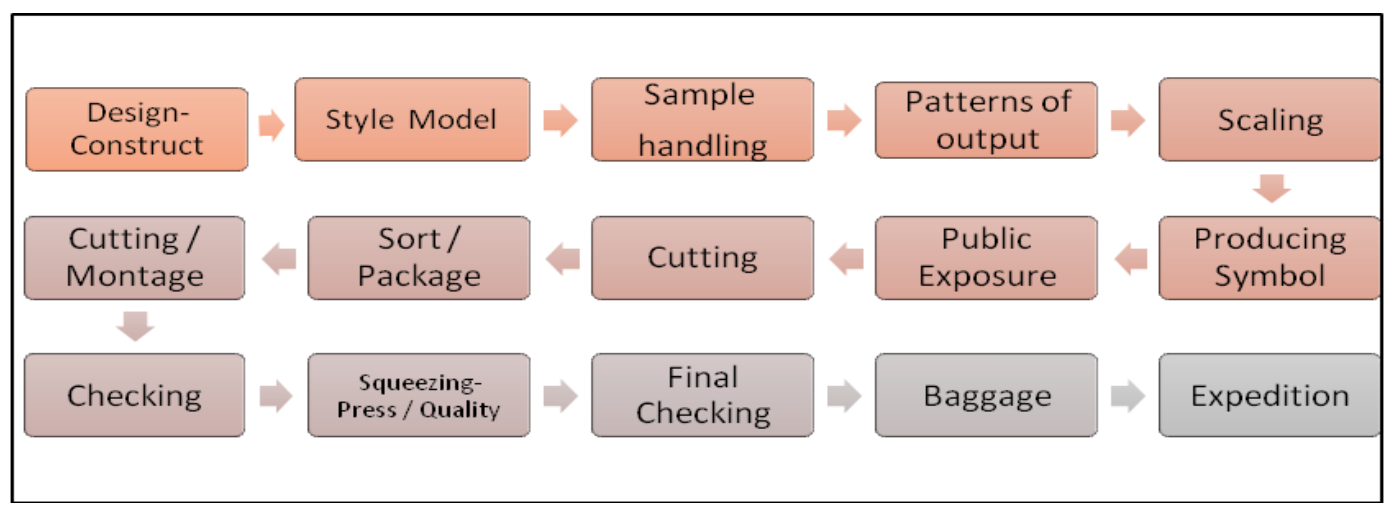

Apparel production companies have various departments or divisions and may include research and merchandising - design and product development.

\subsection{Implementation of TQM}

These stages are summarized as below (Richard, 2005; Weaver, 1995; Oakland, 1993; Ross, 1993; Berry, 1991);

Stage 1: Identification and Preparation.

Stage 2: Management Understanding and Commitment the success of a company sometimes depends on the top managers' single-minded approach to dealing with company problems.

Stage 3: Scheme for Improvement: For the development of a quality improvement scheme, it is necessary to identify the quality problems in each division, each department and throughout the whole organisation.

Stage 4: Critical Analysis: For a review and critical analysis, it is necessary to obtain the information about success and its quantification in order to understand the further requirements for quality progress.

The textiles and apparel sectors are in the short term candidates for diverse industries (Syduzzaman et al., 2014; Islam \& Khan, 2013; Balaji, 2012).

- $\quad$ No manufactured goods danger is available. Turkey is one of the few countries in the world with sufficient capacity for raw materials.

- There is an essential prerequisite to be interested with promotions and distribution platforms. New marketing and supply channels investments are therefore increasing in the target markets.

- Sectorial international exchange firms will reduce selling and distribution issues for small and medium-sized enterprises.

- To boost corporations' profits, the government has begun offering 
- Brand analysis assistance

- $\quad$ Opening, store and server assistance in international nations.

- $\quad$ Support for international fairs participating.

- $\quad$ Encouraging education in foreign trade.

- $\quad$ Support for professional workers.

- Environmental awareness support.

\section{STRATEGIC PLANNING ON THE APPLICATION OF PRINCIPLES OF TOTAL QUALITY MANAGEMENT}

Leadership or Management of a business is an essential consideration for the performance of an organisation. While successful leadership is not the only component of high performance, it is important to improve it. From total destruction into a powerful and proud organization, effective leadership can transform the organization into effective guidance and supervision. Leadership thus has a powerful effect on an individual's behavior to leverage the capacity for achievement of organizational performance. Leadership has been one of the subjects of growing emphasis in researchers' interest (Mustafa \& Bon, 2012; Day \& Zaccaro, 2007; Juran, 1989).

A well-managed quality improvement process (QIP) can help a company achieve that lofty goal and the benefits are real and unbeatable A QIP can provide a company with a sustainable competitive advantage of significant proportions. Some of the benefits to be achieved as below (Garvin, 1998; Cartin, 1993; Bound et al., 1995; Juran, 1989);

- Improving profitability,

- Increasing customer retention,

- $\quad$ Reducing customer complaints and warrant claims.

- $\quad$ Reducing costs through less waste, rework, and so on,

- Greater market sharing,

- Increasing employee involvement and satisfaction, lower turnover,

- Increasing ability to attract new customers.

The applications tend to plan these questionnaires for all workers, consumers, clients, providers, and workers in this field, as TQM needs the recognition and assistance of points where they are unhappy with industry. These questionnaires are classified according to the fields. These are listed as below;

\section{Comments on requires}

- Which easily does the business react to enquiries from its customers?

- How acceptable is the time taken to respond?

- How does the business react, giving the details that they want to their customers?

- What kind of details will they want?

- How well does the business suit its needs to position orders in this way?

- How effective are the employees of the business at managing technological queries?

- How do they help represent our customers?

\section{Cost Expenditure Questions}

- Why do the costs of businesses align with those of like-minded suppliers?

- Where does the firm stand to give them value for money? 


\section{Delivery Query}

- $\quad$ Are they consumer friendly?

- What are the lead times for delivery?

- Which should have been acceptable?

- How frequently does the firm fail to deliver on time?

- $\quad$ And how late are the deliveries when it does?

- Which reliable is the company to let consumers know if the supplies are not going to arrive on time?

- How critical is the business shipping to a given period for customers?

- What is appropriate for them at that time?

All topics were divided into two regions as stated in the questionnaire methodology according to the significance and satisfaction levels of the participants on each subject.

The six topics are seen in the following diagram due to answers of the questionnaire methodology among many of the subjects falling within each continent.

\section{Figure 2: Region of Opportunities and Strengths Chart}
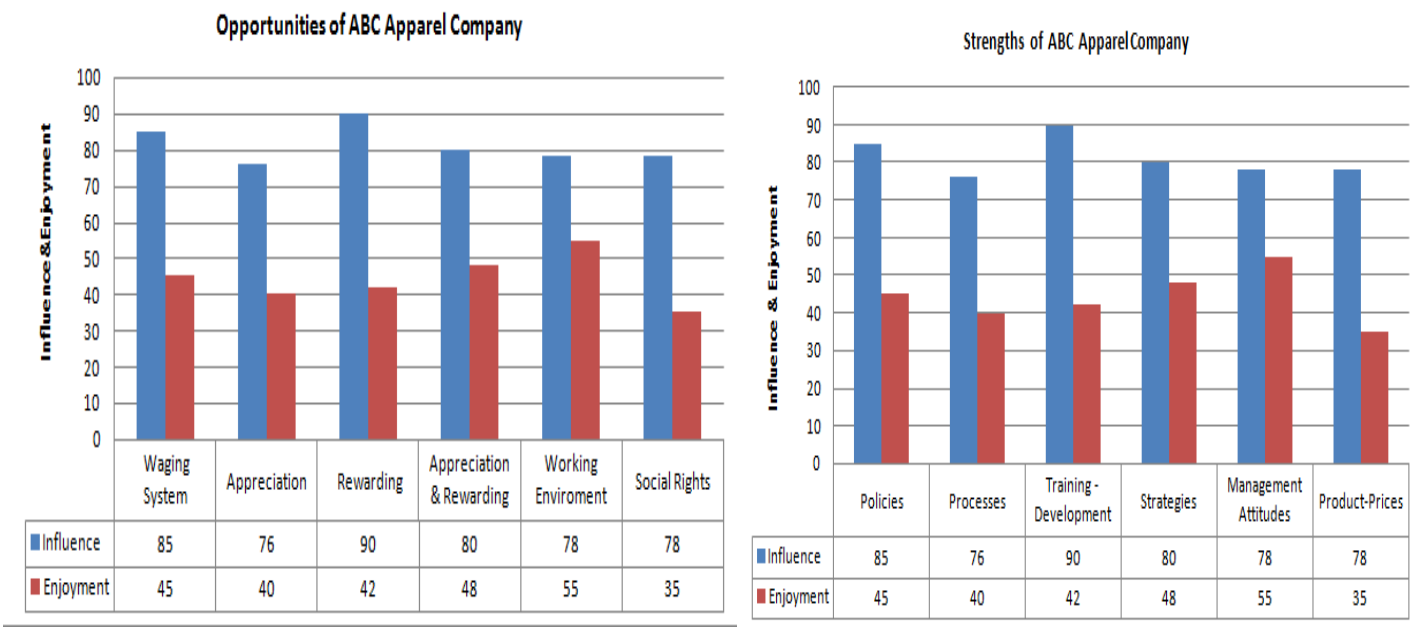

(i) Region of Opportunities: The subjects in this region are those having an importance score higher than the average and a satisfaction score lower than the average. This means that although people attach an extreme importance to these subjects, $A B C$ Business does not meet their expectations. Therefore, each subject in this region can be seen as an opportunity to increase the satisfaction Level. ABC Business should pay much more attention to these subjects and make some improvements in these fields.

(ii) Region of Strengths: This is the region of subjects that people are satisfied with and give importance to for these subjects, $A B C$ Business seems to meet people's expectations and make them happy. The only thing that must be done is to sustain the current satisfaction level; therefore, there is no urgent need to make improvements.

Policies and Strategies: People of ABC business consider keeping up with technological developments as an important subject. Additionally, defining tasks and responsibilities clearly is a subject which managers and officials deem important.

Appreciation and Rewarding: Although appreciation of success and effort is the subject to which all people attach the highest importance, they do not give the same importance to the existence of a clear and written appreciation and rewarding system. Managers have greater expectations of the issues related with appreciation and rewarding system than workers and officials do. 
Social Rights and Waging System: People believe that issues related with payment system are very important, as usual in many companies. Being provided with social rights and being able to purchase company's products easily are not taken into account by managers; however, they are considered as important by workers and officials.

A significant result is that determination of wages and salaries according to personal qualifications and job done possess the highest importance for all people, regardless of the educational level. While quality of food and transportation services is of considerable importance for primary and secondary school graduates, they do not care about job safety.

People appreciate their company for keeping up with technological developments; however, this satisfaction decreases as educational-training level increases. Another subject causing unhappiness among people with high educational-training level is that organisational structure, tasks and responsibilities are not clear yet.

Management Attitudes: Reliable communication and criticisms made on the job not on the personality are the two subjects, which are considered as extremely important by all people, regardless of their positions. Moreover, workers are less interested in how performances are evaluated whereas managers give much importance to the existence of a clear and written performance evaluation system. Additionally, consideration of needs and wants by managers, supports for improving technical and professional skills are the most important issues for officials.

Working Environment: While workers and officials primarily give importance to a comfortable, clean and peaceful working environment and teamwork, for managers, reliable communication, being open to criticism and correction of faults have prior importance Moreover, holding meetings effectively and being ready for meetings on time are of considerable importance for officials and managers rather than for workers.

Cleanliness and comfort of the working environment gains more importance as the educational level increases. The only exception is that postgraduates give as much importance to these issues as people graduated from primary school. Easy access to tools and equipment, harmony and co-ordination among people, and attending meetings at predetermined times are more strongly considered by people with higher educational level one interesting point is that postgraduates attach less importance to teamwork than university and high school graduates do.

\section{CONCLUSION}

All people are highly pleased with determining the vision, mission and values altogether as the strategy of the business. One of the subjects that almost all people complain about is that organisational structure, tasks and responsibilities are not clear yet. While workers think that $A B C$ Textile Company utilises from their performance effectively, managers and officials do not agree with them. A significant result about social rights and payment system is that the employees of $A B C$ Textile Company become unsatisfied with the payment system as educational level increases. In addition, dissatisfaction resulting from working hours and number of working days is directly proportional with the educational level.

People appreciate their company for keeping up with technological developments; however this satisfaction decreases as educational level increases. Another subject causing unhappiness among people with high educational level is that organisational structure, tasks and responsibilities are not clear yet. While considering the fact that the essential goal of TQM was to achieve a satisfaction level among all partners of an organisation at least it aimed and to improve and sustain this satisfaction level on a continual basis.

Everybody is delighted to decide the dream regarding to government and strategy as the purpose and principles overall. One of the issues in which almost everybody worries is that the organizational framework, roles and obligations are still not simple. While employees think the $A B C$ Business utilizes its money effectively, administrators and officials do not agree with them. An essential fact of the civil justice and wage structure is that this company's workers are unsatisfied with the salary program as the standard of employment rises. In fact, the dissatisfaction that results from working hours and the number of working days is directly linked to the degree of employment.

People respect your company as you keep pace with technical developments; however, the cost of education rises. Another issue that causes discontent for highly educated individuals is the fact that the organisation's context, authority and duties are still unclear. Taking into consideration that the main aim of TQM was to achieve at least a certain degree satisfaction between all employees and to develop and expand this sense of happiness continuously. 


\section{REFERENCES}

Abbas, J. \& Sağsan, M. (2019). Impact of knowledge management practices on green innovation and corporate sustainable development: a structural analysis, Journal of Cleaner Production, 229, 611-620, 10.1016/j.jclepro.2019.05.024.

Anderson, J.A. (2010). Evolution of The Health Care Quality Journey, The Journal of Legal Magazine. 31, 59-72. https://doi.org/10.1080/01947641003598252.

Balaji, PK. (2012). Quality Control in Apparel production, Research Journal of Management Sciences, ISCA, 2(2), 57-69.

Backström, T., Fundin, A. \& Johansson, P.E. (2017). Innovative quality improvements in operations: introducing emergent quality management. USA: Springer International Publishing.

Berry, T. H. (1991), Managing the Total Quality Transformation, McGraw-Hill, First Edition, USA.

Bounds, G., Yorks, L., Adams, M. \& Ranney, G. (1995). Total Quality Management Toward the Emerging Paradigm, (Mcgraw Hill Series In Management), McGraw-Hill Education Singapore, 817 p., ISBN-13: 978-0070066786.

Cartin, Thomas, J.(1993). Principles and Practices of TOM, ASQC Quality Press, Wisconsin, p.14.

Cho, Y.S., Jung, J.Y. \& Linderman, K. (2017). The QM Evolution: Behavioral Quality Management as a Firm's Strategic Resource, Journal of Production Economics, 191, http://dx.doi.org/10.1016/j.ijpe.2017.05.002.

Dahlgaard-Park, S.M., Chen, C.K., Jang, J.Y. \& Dahlgaard, J. (2013). Diagnosing and prognosticating the quality movement - a review on the 25 years quality literature (1987-2011). Total Quality Management, 24(1), 1-18.

Simpson, M., Padmore, J. \& Newman, N. (2012). Towards a new model of success and performance in SMEs. International Journal of Entrepreneurial Behaviour and Research, 18, 264-285.

Das, A., Kumar, V. \& Kumar, U. (2011), The role of leadership competencies for implementing TQM: an empirical study in Thai manufacturing industry, International Journal of Quality and Reliability Management, 28(2), 195-219.

Day, D.V. \& Zaccaro, S, J, (2007). Leadership: A critical historical analysis of the influence of leader traits. In Loupes (Ed.) Historical perspectives in industrial and organizational Psychology, 383-405, Mahwah NJ: Lawrence Erbium.

Dean, J.W. \& Bowen, D.E. (1994). Management theory and total quality: Improving research and practice through theory development, Academy of Management Review, 19(3), 392-418.

Dedhia, N.S. (2005). Six Sigma Basics. Total Quality Management and Business Excellence, 16 (5), 567-574. http://dx.doi.org/10.1080/14783360500077468.

Mustafa, A. \& Bon, A.T. (2012) Role of top management leadership and commitment in total quality Management in service organization in Malaysia: A review and conceptual Framework. Elixir Human Resource Management, 51, 11029-11033.

Fundin, A., Bergman, B. \& Elg, M. (2017). The quality dilemma: Combining development and stability. In: Backström, T., Fundin, A., Johansson, P.E., (Eds.). Innovative quality improvements in operations: introducing emergent quality management. USA: Springer International Publishing, $9-33$.

Fundin, A., Bergquist, B., Eriksson, H. \& Gremyr, I. (2018). Challenges and propositions for research in quality management, International Journal of Production Economics, 199, doi: 10.1016/j.ijpe.2018.02.020.

Fotopoulos, C.V., \& Psomas, E.L.(2010). The structural relationships between TQM factors and organisational performance. Total Quality Management and Business Excellence, 22(5), 539-552.

Garg, A. and Goyal, D.P. (2012). Striving towards strategic alignment in SMEs: an empirical analysis. Journal of Advances in Management Research, 9, 77-95.

Garvin, D. A. (1998). Managing Quality: The Strategic and Competitive Edge, First Edition, Free Press, New York, 319 pages, ISBN-13: 9780029113806.

Gioia, D.A. and Pitre, E. (1990). Multiparadigm Perspectives on Theory Building, Academy of Management. The Academy of Management Review, 15, 584-595.

Gupta, R., Pandey, A.K. \& Purohit, H. (2012), Do HR competencies differ across industries and roles?, 4d International Journal of Management and Science, 52-58.

Imai, M. (1986). Kaizen: The Key to Japan's Competitive Success, Random House, New York. 
Islam, Md. M. \& Khan, A, M. (2013). Application of Lean Manufacturing to Higher Productivity in the Apparel Industry in Bangladesh, International Journal of Scientific and Engineering Research, 4(2), 1-10. ISSN 2229-5518.

Jabonski, J. R. (1994). Implementing TQM: Competing in the 90s Through Total Quality Management, 2nd Second Edition and Michigan USA, ISBN-13: 978-1878821034, $224 \mathrm{p}$.

Johnson, R. S. (1993). Management Processes for Quality Operations, Milwaukee, WI: ASQC Quality Press, USA.

Jusoh, R. \& Parnell, J. (2008). Competitive strategy and performance measurement in the Malaysian context: An exploratory study. Management Decision, 46, 5-31.

Kanji, G.K. (1996). Can total quality management help innovation? Total Quality Management, 7 (1), 3-9.

Kanji, G.K. \& Asher, M. (1993). Total Quality Management process, a systematic approach, Advances in Total Quality Management Series, 4, Carfax Publishing, Abingdon.

Khanna, V. \& Gupta, R. (2014). Comparative study of the impact of competency-based training on 5 S and TQM: A case study, International Journal of Quality and Reliability Management, 31(3), 238-260.

Kelada, J.N. (1996). Integrating Reengineering with Total Quality, Asq Pr-ASOC Quality press Publications., Wisconsin, ISBN-13: 978-0873893398.

Li, D., Zhao, Y., Zhang, L., Chen, X. \& Cao, C. (2018). Impact of quality management on green innovation, Journal of Cleaner Production, 170, 462470.

McAdam, R., Miller, K. \& McSorley, C. (2016). Towards a contingency theory perspective of quality management in enabling strategic alignment, Journal of Production Economics, 207, http://dx.doi.org/10.1016/j.ijpe.2016.07.003.

Macchion, L., Moretto, A., Caniato, F., Caridi, M., Danese, P. \& Vinelli, A. (2015). Production and Supply Network Strategies within the Fashion Industry, International Journal of Production Economics, 163, 173-188.

Mahesh, C. (1993). Total quality management in management development, Journal of Management Development, 12(7), 19-31.

Mahmood, H.K., Hashmi, M.S., Shoaib, D.M., Danish, R. \& Abbas, J. (2014). Impact of TQM practices on motivation of teachers in secondary schools' empirical evidence from Pakistan, Journal of Basic and Applied Scientific Research, 4, 1-8.

Martinich, Joseph, S. (1997). Production and Operations Management, an Applied Modern Approach, New York: John Willey and Sons, Inc.

Morgan, L. R. \& Birtwistle, G. (2009). An investigation of young fashion consumers' disposal habits. International Journal of Consumer Studies, 33(2), Blackwell Publishing, 190-198.

Ngambi, M.I T. \& Nkemkiafu, A. G. (2015). The Impact of Total Quality Management on Firm's Organizational Performance, American Journal of Management, 15(4), 69-70.

Oakland, J. (2005). From Quality to Excellence in the 21st Century. Total Quality Management. 16 (8-9), 1053-1060.

Oakland, J. (1993). Total Quality Management: The Route to Improving Performance, Nichols Publishing Company; 2nd Edition, Great Britain, p. 463, ISBN-13: 978-0893973865.

Ooi, K.B. (2014). TQM: a facilitator to enhance knowledge management? A structural analysis, Expert Systems with Applications, 41, 5167-5179.

Plessis, F. \& Beer, H. (2010), Generic competencies for performance mangers, Journal of European Industrial Training, 37(1), 69-80.

Porter, L.J., \& Parker, A.J. (1993). Total Quality Management: The critical success factors. Total Quality Management. 4(1), 810-829.

Powell, T. C. (1995). Total Quality Management as Competitive Advantage: A Review and Empirical Study. Strategic Management Journal, 16, 1537. https://www.jstor.org/stable/2486944.

Prajogo, D.I. \& Sohal, A.S. (2001). TQM and innovation: A literature review and research framework, Technovation, 21(9), 539-558.

Qaiser, S. \& Rizwana, G. (2015), Challenges to Successful Total Quality Management Implementation in Public Secondary Schools: A Case Study of Kohat District, Pakistan, Journal of Education and Practice, 6(15), p.123.

Rahman, S. \& Bullock, P.(2005). Soft TQM, hard TQM, and organisational performance relationships: an empirical investigation. OmegaInternational Journal of Management Science, 33, 73-83.

Raymond, L. \& St-Pierre, J. (2013). Strategic capability configurations for the internationalization of SMEs: A study in equifinality. International Small Business Journal, 31, 82-102.

Reed, R., Lemak, D.J. \& Montgomery, J.C. (1996). Beyond process: TQM content and firm performance, Academy of Management Review, 21(1), 173-202. 
Roffe, I. (1999). Innovation and creativity in organisations: A review of the implications for training and development, Journal of European Industrial Training, 23(4/5), 224-237.

Ross, J.E. (1993). Total Quality Management: Text, Cases and Readings, Boca Raton, F.L: St. Lucie Press. 2 Edition, USA Florida.

Samaha, H.E. (1996). Overcoming the TQM barrier to innovation, HR Magazine, 41(6), 145-149.

Samat, N., Ramayah, T. \& Saad, N. M. (2006). TQM practices, service quality, and market orientation. Management Research News, 29 (11), 713728. DOI 10.1108/01409170610716025.

Schroeder, R. G., Linderman, K. \& Zhang, D. (2005). Evolution of Quality: First Fifty Issues of Production and Operations Management. Production and Operations Management Society. 14 (4), 468-481. https://doi.org/10.1111/j.1937-5956.2005.tb00234.x.

Seinor, B., \& Swailer, S. (2004). The dimensions of management team performance: A repertory grid study. International Journal of Productivity and Performance Management, 53(4), 317-333. doi: 10.1108/17410400410533908.

Sila, I. (2007). Examining the effects of contextual factors on TQM and performance through the lens of organizational theories: an empirical study, Journal of Operations Management, 25, 83-109, 10.1016/j.jom.2006.02.003.

Slater, S.F. \& Narver, J.C. (1998). Customer-led and market-led: Let's not confuse the two, Strategic Management Journal, $19(10), 1001-1006$.

Sousa, R. \& Voss, C.(2008). Contingency research in operations management. Journal of Operations Management, 26, 697-713.

Syduzzaman, S., Rahman, M., Islam, M., Habib, A. \& Ahmed, S. (2014). Implementing Total Quality Management Approach In Garments Industry, European Scientific Journal, 10 (34), 1857- 7431.I SSN: 1857 - 7881.

Vanichchinchai, A. \& Igel, B.(2011). The impact of total quality management on supply chain management and firm's supply performance. International Journal of Production Research, 49(11), 3405-3424.

Wilkinson, C, N. (1995). Managing the Four Stages of TQM: How to Achieve World-Class Performance, American Society for Quality Control, USA, 252 p., ISBN-13: 978-0873893114 1995.

Wilkinson, A. (1992). The other side of quality: 'soft' issues and the Human resource dimension. Total Quality Management, 3(3), 323-329.

Wind, J. \& Mahajan, V. (1997). Issues and opportunities in new product development: An introduction to the special issue, Journal of Marketing Research, 34(1), 1-12.

Yeung, A.C., Cheng, T.E. \& Chan, L.Y. (2004). From customer orientation to customer satisfaction: The gap between theory and practice. IEEE Transactions on Engineering Management, 51, 85-97.

Yong, J. \& Wilkinson, A. (2002). The long and winding road: The evolution of quality management. Total Quality Management, 13(1), 101-121, https://doi.org/10.1080/09544120120098591.

Yusr, M.M., Mokhtar, S.S.M., Othman, A.R. \& Sulaiman, Y. (2017). Does interaction between TQM practices and knowledge management processes enhance the innovation performance? International Journal of Quality and Reliability Management, 955-974.

Zhou, B. (2012). Lean principles, practices, and impacts: a study on small and medium-sized enterprises (SMEs), Annals of Operations Research, 457-474. 